\title{
Determination of Young's and shear moduli of common yew and Norway spruce by means of ultrasonic waves
}

\author{
Journal Article \\ Author(s): \\ Keunecke, Daniel; Sonderegger, Walter; Pereteanu, Karol; Lüthi, Thomas; Niemz, Peter \\ Publication date: \\ 2007 \\ Permanent link: \\ https://doi.org/10.3929/ethz-b-000005142 \\ Rights / license: \\ In Copyright - Non-Commercial Use Permitted \\ Originally published in: \\ Wood Science and Technology 41(4), https://doi.org/10.1007/s00226-006-0107-4
}




\title{
Determination of Young's and shear moduli of common yew and Norway spruce by means of ultrasonic waves
}

\author{
Daniel Keunecke $\cdot$ Walter Sonderegger • \\ Karol Pereteanu · Thomas Lüthi · Peter Niemz
}

Received: 6 May 2006/Published online: 3 November 2006

(C) Springer-Verlag 2006

\begin{abstract}
Despite the exceptional position of yew among the gymnosperms concerning its elastomechanical properties, no reference values for its elastic constants apart from the longitudinal Young's modulus have been available from literature so far. Hence, this study's objective was to determine the Young's moduli $E_{\mathrm{L}}, E_{\mathrm{R}}$ and $E_{\mathrm{T}}$ and the shear moduli $G_{\mathrm{LR}}, G_{\mathrm{LT}}$ and $G_{\mathrm{RT}}$ of yew wood. For that purpose, we measured the ultrasound velocities of longitudinal and transversal waves applied to small cubic specimens and derived the elastic constants from the results. The tests were carried out at varying wood moisture contents and were applied to spruce specimens as well in order to put the results into perspective. Results indicate that $E_{\mathrm{L}}$ is in the same order of magnitude for both species, which means that a high-density wood species like yew does not inevitably have to have a high longitudinal Young's modulus. For the transverse Young's moduli of yew, however, we obtained 1.5-2 times, for the shear moduli even 3-6 times higher values compared to spruce. The variation of moisture content primarily revealed differences between both species concerning the shear modulus of the RT plane. We concluded that anatomical features such as the microfibril angle, the high ray percentage
\end{abstract}

D. Keunecke $(\varangle) \cdot$ W. Sonderegger $\cdot$ P. Niemz

Institute for Building Materials (Wood Physics Group),

ETH Zurich, Zurich, Switzerland

e-mail: keunecke@ifb.baug.ethz.ch

K. Pereteanu

Faculty of Mechanical Engineering,

Department of Strength of Materials and Vibrations,

University Transilvania of Brasov, Brasov, Romania

T. Lüthi

Swiss Federal Laboratories for Materials Testing and Research,

Electronics/Metrology, Empa, Zurich, Switzerland 
and presumably the large amount of extractives must fulfil important functions for the extraordinary elastomechanical behaviour of yew wood which still has to be investigated in subsequent micromechanical studies.

\section{Introduction}

The exceptional position of yew wood within the gymnosperms is well known. Even though based on only few studies, yew wood is classified as extremely dense, hard, tough and highly elastic (Sell 1997). Primarily due to its high elasticity, it was common practice to make arms such as bows, lances and crossbows from yew wood in earlier centuries (Bariska 1998). Mainly the longitudinal Young's modulus of yew as an indicator of wood stiffness has already been investigated. The published results vary strongly; an unusual wide range from 6,200 to $15,700 \mathrm{MPa}$ can be found in literature (Markwardt and Wilson 1935; Sekhar and Sharma 1959; Jakubczyk 1966; Sell 1997; Wagenführ 2000).

Usually, a strong species-spanning correlation between density on the one hand and strength and elasticity on the other hand is given. In this regard yew wood seems to be an outlier. In our preliminary investigations (Märki et al. 2005), we found, despite large density differences, the Young's modulus in bending of yew to be more or less in the same order of magnitude as that of spruce wood.

For a better understanding of the extraordinary elastomechanical behaviour of yew wood, however, the examination of further elastic constants is indispensable. Thus, the aim of this study was to determine the Young's moduli $E_{\mathrm{L}}, E_{\mathrm{R}}$ and $E_{\mathrm{T}}$ and the shear moduli $G_{\mathrm{LR}}, G_{\mathrm{LT}}$ and $G_{\mathrm{RT}}$ of small yew (Taxus baccata L.) and spruce cubes (Picea abies [L.] Karst.) by means of ultrasonic waves. While we were mainly interested in yew properties, the tests were applied to spruce wood from the same stands too, in order to put the results into perspective.

The measurements have been applied under standard climatic conditions and also at varying wood moisture contents within the hygroscopic range, mainly for two reasons:

- The moisture content strongly influences the elastic behaviour of wood. For yew wood, however, no investigations into this correlation are available from literature.

- The large amount of yew extractives results in a lower relative water vapour adsorption for yew compared to spruce.

The use of sound velocities for the determination of elastic constants is well accepted and has frequently been applied (e.g. Lee 1958; Kollmann and Krech 1960; Burmester 1965; Becker 1967; Bucur 1995). For our purposes, this method was appropriate since it provided several advantages: 
- As a result of the cube size, we were able to produce nearly faultless yew specimens even though weak points such as knots and irregular grain are typical for yew. Furthermore, the pronounced curved nature of tree rings in consequence of the small trunk diameters of yew wood has a lower impact on small specimens.

- The ultrasonic method is non-destructive, i.e. nine ultrasound velocities $\left(c_{\mathrm{LL}}, c_{\mathrm{RR}}, c_{\mathrm{TT}}, c_{\mathrm{LR}}, c_{\mathrm{RL}}, c_{\mathrm{RT}}, c_{\mathrm{TR}}, c_{\mathrm{TL}}\right.$ and $\left.c_{\mathrm{LT}}\right)$ can be measured for each specimen. Moreover, the moisture influence can always be observed for the same specimens.

- The determination of shear moduli is complicated and imprecise; no standards are defined. It is difficult to generate pure shear stresses in a specimen and to measure the corresponding strain correctly. Besides dynamic procedures such as eigenfrequency (Görlacher 1990), direct determination by means of cubes or disks and indirect determination by means of torsion (Schwab and Polaczek 1977) are reported. Further comprehensive overviews of suitable methods are given by Ehlbeck (1967) and Albers (1970). Due to the specimen size, we reduced the influence of tree ring inclination (i.e. the angle between the radial and tangential direction) on the shear load in the RT plane to a minimum.

With this study, we wanted to evaluate

- whether we can confirm the longitudinal Young's modulus of yew to be actually in the same order of magnitude as that of spruce as we found in our preliminary tests (Märki et al. 2005),

- whether the transverse stiffness and the shear moduli are higher for yew due to its higher cell wall/lumen aspect ratio compared to spruce and

- whether, despite the high density, the short yew tracheids together with their irregular grain cause a lower longitudinal sound velocity compared to spruce.

\section{Materials and methods}

\section{Material}

Cubic specimens of clear wood were cut from $2.5 \mathrm{~m}$ long bottom stem sections of two yews and two spruce stems from stands close to Zurich, Switzerland. The yew stems contained $\sim 120$ and 180 tree rings, both spruce stems $\sim 100$ tree rings. The samples were evenly distributed over the whole stem sections, both in horizontal and vertical direction; specimens with compression wood were rejected. The cube surfaces were planar and parallel; the edges were $10 \mathrm{~mm}$ long in the longitudinal, radial and tangential direction.

The specimens were divided into two groups: (group 1) 120 specimens per wood species were climatized for sound velocity measurements under standard climatic conditions $\left(20^{\circ} \mathrm{C}\right.$ and $\left.65 \% \mathrm{RH}\right)$. (group 2) Another 14 specimens 
per wood species were prepared for measurements under four different climatic conditions in order to vary the moisture content. Therefore, they were initially stored in a climatic chamber at $20^{\circ} \mathrm{C}$ and $35 \% \mathrm{RH}$ until they reached equilibrium moisture content; subsequently the sound velocities were measured. With the same specimens, this procedure was repeated for another three climatic conditions with increasing relative humidity $\left(20^{\circ} \mathrm{C} / 65 \% \mathrm{RH}\right.$, $\left.20^{\circ} \mathrm{C} / 80 \% \mathrm{RH}, 20^{\circ} \mathrm{C} / 95 \% \mathrm{RH}\right)$.

\section{Measurement of ultrasound velocity}

The sound velocity measurements were carried out with a USK 7D (KRAUTKRÄMER) flaw detector. A constant contact pressure was guaranteed by the clamping apparatus (Fig. 1). Two types of coupling from transducer to sample were deployed: honey for group 1 and $0.3 \mathrm{~mm}$ thick selfadhesive carbon plates (PROVAC), usually used for the preparation of samples for scanning electron microscopy, for group 2. The advantage of carbon plates was that the coupling medium could be removed and did not penetrate into the specimens. Otherwise a repeated climatic conditioning of the samples would have been impossible due to plugged cell cavities.

The elastic constants were determined by means of two wave types. The Young's moduli were calculated on the basis of the sound velocity of longitudinal waves generated with a GX203 (UTX) transducer $(10 \mathrm{MHz}, \varnothing$ $12.7 \mathrm{~mm})$. The velocity of transverse waves, generated with an S-0104 (STAVELEY) transducer $(1 \mathrm{MHz}, \varnothing 12.7 \mathrm{~mm})$, was used to determine the shear moduli. Since considerable attenuation and scattering occurs at high frequencies and signals are partly reflected at cell walls and earlywood-latewood interfaces, the measurements were based on the transmitting pulse method instead of the conventional pulse-echo-overlap method.

Sound velocities have the general form $c_{i j}$, where $i$ is the direction of wave propagation and $\mathrm{j}$ the direction of oscillation. For longitudinal waves $i=j$ is given, for transverse waves $i \neq j$. As a result, three sound velocities had to be

Fig. 1 Clamping apparatus, sensors and a cubic specimen

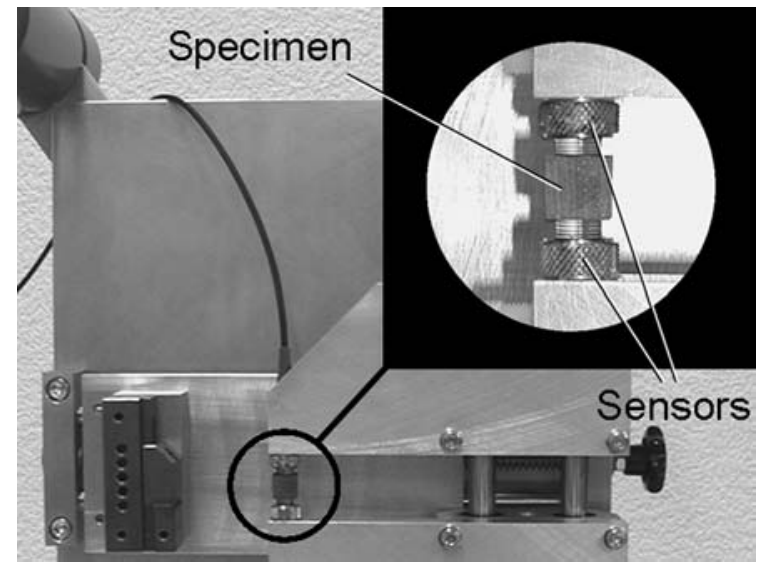


measured with longitudinal waves, another six with transverse waves. As an approximation, orthorhombic symmetry can be assumed for the cubic specimens. Therefore, the direction of wave propagation and the direction of oscillation are exchangeable for transverse waves $\left(c_{i j}=c_{j i}\right)$.

In the case of longitudinal waves, the peak of the first received wave was amplified to $90 \%$ of the display scale; the delay of the signal was measured at the flank of the first incoming wave at $80 \%$ of the display scale. The same procedure was carried out for transverse waves. However, the detection of the first transverse wave was partly difficult in the RL, LR, TL and LT directions due to overlap effects with longitudinal waves. For the calculation of ultrasound velocity, it has to be taken into consideration that besides the specimen itself, the sound waves have to propagate through the protective layer covering the oscillator of the transducer and through the coupling medium as well. Thus, the system had to be calibrated with an aluminium disk by adjusting it to the sound velocity of aluminium.

\section{Calculation of Young's and shear moduli}

The tensor of elastic stiffness $S$ for wood can be approximated as

$$
S=\left[\begin{array}{cccccc}
E_{\mathrm{T}}^{-1} & -\mu_{\mathrm{RT}} E_{\mathrm{R}}^{-1} & -\mu_{\mathrm{LT}} E_{\mathrm{L}}^{-1} & 0 & 0 & 0 \\
-\mu_{\mathrm{TR}} E_{T}^{-1} & E_{\mathrm{R}}^{-1} & -\mu_{\mathrm{LR}} E_{\mathrm{L}}^{-1} & 0 & 0 & 0 \\
-\mu_{\mathrm{TL}} E_{T}^{-1} & -\mu_{\mathrm{RL}} E_{\mathrm{R}}^{-1} & E_{\mathrm{L}}^{-1} & 0 & 0 & 0 \\
0 & 0 & 0 & G_{\mathrm{LR}}^{-1} & 0 & 0 \\
0 & 0 & 0 & 0 & G_{\mathrm{LT}}^{-1} & 0 \\
0 & 0 & 0 & 0 & 0 & G_{\mathrm{RT}}^{-1}
\end{array}\right]
$$

with a total of 15 independent constants. Similar approximations are made for long (hollow) bones in anatomy, however, with a higher symmetry than we found for wood. It is usual to take $S_{33}$ as the dominant value. An analysis of the results of Neuhaus (1981, for spruce) shows that only the values for $S_{12}$ and $S_{21}$ are very similar. An inversion into the tensor of elastic compliance $C$ (under the given conditions) shows that there is the following relation:

$$
\frac{c_{\mathrm{RR}}^{2}}{c_{\mathrm{TT}}^{2}} \approx \frac{E_{\mathrm{R}}}{E_{\mathrm{T}}} \approx \frac{\mu_{\mathrm{RT}}}{\mu_{\mathrm{TR}}}
$$

where the diagonal elements of $C$ correspond to the ultrasonic velocities as $C_{11}=\rho c_{\mathrm{TT}}^{2}$ (longitudinal wave velocity along axis $\mathrm{T}$ ), $C_{22}=\rho c_{\mathrm{RR}}^{2}$ (longitudinal wave velocity along axis $\mathrm{R}$ ), $C_{33}=\rho c_{\mathrm{LL}}^{2}$ (longitudinal wave velocity along axis $\mathrm{L}$ ), $C_{44}=\rho c_{\mathrm{LR}}^{2}$ (shear wave velocity along axis $\mathrm{LR}=\mathrm{RL}$ ), $C_{55}=$ $\rho c_{\mathrm{LT}}^{2}$ (shear wave velocity along axis $\mathrm{LT}=\mathrm{TL}$ ), and $C_{66}=\rho c_{\mathrm{RT}}^{2}$ (shear wave 
velocity along axis RT $=\mathrm{TR}$ ) with $\rho$ as the raw density. While the inversion of the measured values for the shear moduli can be made directly by using the above given relations

$$
G_{i j}=c_{i j}^{2} \rho
$$

an inversion of the terms resulting in Young's moduli and Poisson's ratios will fail, as not enough constants are known. A frequent approach is to use the relation for shear moduli for the Young's moduli, as well, as

$$
E_{i}=c_{i i}^{2} \rho
$$

However, even for a perfectly isotropic system this is only successful if the Poisson's ratio is very small, as it does not consider any transverse contraction of the sample (similar to a spring). The usual difference between the two values measured dynamically (with ultrasound velocity and direct conversion) and statically (mechanically) is highly dependent on the Poisson's ratio and lies, for an isotropic system, between $10 \%(\mu=0.2)$ and $50 \%(\mu=0.4)$; the dynamic value is always higher (the use of the terms "dynamic" and "static" in general literature is not distinct).

Applying the values of Neuhaus (1981) to such a comparison, we found differences in L-direction of $9 \%$ and in R- and T-direction, respectively, of $34 \%$; the same values in $\mathrm{R}$ - and $\mathrm{T}$-direction are the result of the similarities given above. Furthermore, any relations as used for bones between $C_{66}, C_{11}$ and $C_{12}$, and in the case of wood also of $C_{22}$, cannot be found.

In absolute values in $\left(\mathrm{kN} / \mathrm{mm}^{2}\right)^{-1}$ the upper left part of the stiffness tensor given by Neuhaus (1981) is

$$
S=\left[\begin{array}{ccc}
2.4752 & -0.7962 & -0.0515 \\
-0.7995 & 1.2658 & -0.0366 \\
-0.0866 & -0.0696 & 0.0840
\end{array}\right]
$$

and its inversion in $\left(\mathrm{kN} / \mathrm{mm}^{2}\right)$

$$
C=\left[\begin{array}{ccc}
0.5395 & 0.3663 & 0.4904 \\
0.3656 & 1.0577 & 0.6853 \\
0.8594 & 1.2544 & 12.9788
\end{array}\right]
$$

For a re-inversion it becomes clear, that the terms $S_{11}$ and $S_{22}$ are dominated by the high value of $C_{33}$, while for $S_{33}$ the values of $C_{12}$ and $C_{21}$ are of importance as well.

It may be assumed that all values are influenced by humidity and therefore the difference between the dynamic and the static value of $E_{\mathrm{L}}$ is more highly affected than the other ones and its behaviour can be governed by another regime. 


\section{Results and discussion}

Ultrasonic velocities under standard climatic conditions

As one can see from the overview of the measured ultrasonic velocities (Table 1), we obtained $c_{\mathrm{LL}}>c_{\mathrm{RR}}>c_{\mathrm{TT}}>c_{\mathrm{LR}}>c_{\mathrm{LT}}>c_{\mathrm{RT}}$ for both wood species. This rank order is a consequence of the characteristic mechanical and acoustical orthotropic anisotropy of wood. From the mechanical point of view, sound velocity highly correlates with a material's elasticity since sound waves generate mechanical oscillations. Hence, elasticity of wood strongly varies in the three principal directions. From the acoustical point of view, the gymnosperm structure is a system of closed tubes, which are oriented both in the vertical and horizontal (i.e. radial) direction. Tracheids are vertical tubes with a length-to-diameter aspect ratio of 30:1-100:1 providing high acoustical constancy in the longitudinal direction. Ray cells are horizontal tubes, shorter than tracheids but still suitable to transmit acoustical waves in the radial direction. In the tangential direction, however, a continuous acoustical conducting structure is completely lacking. Consequently, the smallest sound velocities are found in the tangential direction (Bucur 1996).

Sound velocities not only depend on the direction of wave propagation, they also vary among different wood species. Each species features characteristics, which affect the transmission of ultrasonic energy such as physical properties of cell walls or geometrical structure of cells. Each structural element acts independently as an elementary resonator (Bucur 1996); the spatial distribution of these resonators differs from species to species.

The sound velocities we measured for spruce are in the same order of magnitude as the values Bucur (1995) found for spruce. The comparability between our values and bibliographical references, however, is generally complicated since different specimen dimensions, frequencies and coupling media are used in the majority of cases.

Yew and spruce clearly differed in their sound velocities: $c_{\mathrm{LL}}$ was clearly lower, $c_{\mathrm{RR}}$ clearly greater and $c_{\mathrm{TT}}$ slightly higher for yew wood (Table 1 ). The low $c_{\mathrm{LL}}$ of yew wood can be ascribed to several factors:

- Yew tracheids are short compared to spruce tracheids [yew

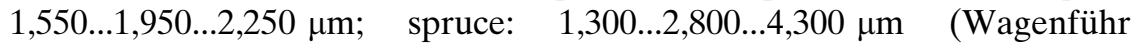
2000)]. According to Burmester (1965), the fastest transmission of sound takes place in the zone with the longest tracheid lumens.

- The high percentage of wood rays [yew 14\%; spruce 4\% (Wagenführ 2000)] causes an irregular grain (Kucera 1998). Sound velocity decreases rapidly with an increasing angular displacement from the longitudinal direction (Lee 1958). In case of spruce, even a displacement of only $10^{\circ}$ results in a $20 \%$ decrease of sound velocity (Niemz et al. 1999). 
Table 1 Overview of the measured ultrasonic velocities (coupling medium: honey)

\begin{tabular}{|c|c|c|c|c|c|c|c|c|c|c|c|c|}
\hline & & $\begin{array}{l}\text { Moisture } \\
\text { content (\%) }\end{array}$ & $\begin{array}{l}\rho \\
\left(\mathrm{g} / \mathrm{cm}^{3}\right)\end{array}$ & $\begin{array}{l}c_{\mathrm{LL}} \\
(\mathrm{m} / \mathrm{s})\end{array}$ & $\begin{array}{l}c_{\mathrm{RR}} \\
(\mathrm{m} / \mathrm{s})\end{array}$ & $\begin{array}{l}c_{\mathrm{TT}} \\
(\mathrm{m} / \mathrm{s})\end{array}$ & $\begin{array}{l}c_{\mathrm{LR}} \\
(\mathrm{m} / \mathrm{s})\end{array}$ & $\begin{array}{l}c_{\mathrm{RL}} \\
(\mathrm{m} / \mathrm{s})\end{array}$ & $\begin{array}{l}c_{\mathrm{LT}} \\
(\mathrm{m} / \mathrm{s})\end{array}$ & $\begin{array}{l}c_{\mathrm{TL}} \\
(\mathrm{m} / \mathrm{s})\end{array}$ & $\begin{array}{l}c_{\mathrm{RT}} \\
(\mathrm{m} / \mathrm{s})\end{array}$ & $\begin{array}{l}c_{\mathrm{TR}} \\
(\mathrm{m} / \mathrm{s})\end{array}$ \\
\hline $\begin{array}{l}\text { Yew } \\
(n=120)\end{array}$ & $\begin{array}{l}\bar{x} \\
v(\%)\end{array}$ & $\approx 11$ & $\begin{array}{l}0.653 \\
11.3\end{array}$ & $\begin{array}{l}5,060 \\
5.0\end{array}$ & $\begin{array}{l}2,520 \\
3.6\end{array}$ & $\begin{array}{l}1,860 \\
6.2\end{array}$ & $\begin{array}{l}1,630 \\
5.2\end{array}$ & $\begin{array}{l}1,640 \\
4.1\end{array}$ & $\begin{array}{l}1,550 \\
4.4\end{array}$ & $\begin{array}{l}1,620 \\
3.9\end{array}$ & $\begin{array}{l}750 \\
3.7\end{array}$ & $\begin{array}{l}751 \\
3.8\end{array}$ \\
\hline $\begin{array}{l}\text { Spruce } \\
(n=120)\end{array}$ & $\begin{array}{l}\bar{x} \\
v(\%)\end{array}$ & $\approx 12$ & $\begin{array}{l}0.399 \\
9.7\end{array}$ & $\begin{array}{l}5,850 \\
8.3\end{array}$ & $\begin{array}{l}2,130 \\
3.1\end{array}$ & $\begin{array}{l}1,710 \\
9.8\end{array}$ & $\begin{array}{l}1,220 \\
4.0\end{array}$ & $\begin{array}{l}1,270 \\
5.6\end{array}$ & $\begin{array}{l}1,210 \\
3.3\end{array}$ & $\begin{array}{l}1,210 \\
3.3\end{array}$ & $\begin{array}{l}366 \\
2.6\end{array}$ & $\begin{array}{l}359 \\
3.0\end{array}$ \\
\hline
\end{tabular}

- The high ray percentage contributes to the enormous density of yew wood but is irrelevant for the fast transformation of ultrasound in the longitudinal direction. On the other hand, the relatively high $c_{\mathrm{RR}}$ of the yew cubes is caused by the high ray percentage.

Elastic constants under standard climatic conditions

Table 2 gives an overview of the elastic constants. Since $G_{\mathrm{LR}}=G_{\mathrm{RL}}$ and $G_{\mathrm{LT}}=G_{\mathrm{TL}}$ and $G_{\mathrm{RT}}=G_{\mathrm{TR}}$ applies to the shear moduli, only the mean of both values is represented in the table. The coefficients of variation are in the common range of solid wood.

\section{Young's moduli}

The density of yew cubes was in the range well known from literature $(0.65 \mathrm{~g} /$ $\left.\mathrm{cm}^{3}\right)$ whereas the spruce cubes were relatively light $\left(0.40 \mathrm{~g} / \mathrm{cm}^{3}\right)$. With a density in the range of literature references $\left[0.47 \mathrm{~g} / \mathrm{cm}^{3}\right.$ (Sell 1997; Wagenführ 2000)], $E_{\mathrm{L}}$ would be in the same region for both yew and spruce since $E_{\mathrm{L}}$ is strongly influenced by the density (as a constant in Eq. 4). This confirms preliminary static tests of our group: Märki et al. (2005) determined a Young's modulus in bending for yew (10,200 MPa), which was even slightly below the value for spruce (11,600 MPa). That indicates that a large longitudinal Young's modulus is not obligatory for high dense wood species. Primarily two reasons are imaginable for the relatively small $E_{\mathrm{L}}$ for yew:

- Even the microfibril angle (MFA) of the normal yew wood is large compared to other softwood species. Specimens with compression wood had been rejected. A small MFA in the thickest tracheid cell wall layer $S_{2}$

Table 2 Overview of the calculated elastic constants (coupling medium: honey)

\begin{tabular}{|c|c|c|c|c|c|c|c|c|c|}
\hline & & $\begin{array}{l}\text { Moisture } \\
\text { content (\%) }\end{array}$ & $\begin{array}{l}\rho \\
\left(\mathrm{g} / \mathrm{cm}^{3}\right)\end{array}$ & $\begin{array}{l}E_{\mathrm{L}} \\
(\mathrm{Mpa})\end{array}$ & $\begin{array}{l}E_{\mathrm{R}} \\
(\mathrm{Mpa})\end{array}$ & $\begin{array}{l}E_{\mathrm{T}} \\
(\mathrm{Mpa})\end{array}$ & $\begin{array}{l}G_{\mathrm{LR}} \\
(\mathrm{Mpa})\end{array}$ & $\begin{array}{l}G_{\mathrm{LT}} \\
(\mathrm{Mpa})\end{array}$ & $\begin{array}{l}G_{\mathrm{RT}} \\
(\mathrm{Mpa})\end{array}$ \\
\hline $\begin{array}{l}\text { Yew } \\
(n=120)\end{array}$ & $\begin{array}{l}\bar{x} \\
v(\%)\end{array}$ & $\approx 11$ & $\begin{array}{l}0.65 \\
11.3\end{array}$ & $\begin{array}{l}16,700 \\
14.4\end{array}$ & $\begin{array}{l}4,180 \\
16.9\end{array}$ & $\begin{array}{l}2,300 \\
23.4\end{array}$ & $\begin{array}{l}1,740 \\
13.0\end{array}$ & $\begin{array}{l}1,650 \\
13.7\end{array}$ & $\begin{array}{l}368 \\
12.0\end{array}$ \\
\hline $\begin{array}{l}\text { Spruce } \\
(n=120)\end{array}$ & $\begin{array}{l}\bar{x} \\
v(\%)\end{array}$ & $\approx 12$ & $\begin{array}{l}0.40 \\
9.7\end{array}$ & $\begin{array}{l}13,800 \\
20.0\end{array}$ & $\begin{array}{l}1,800 \\
10.6\end{array}$ & $\begin{array}{l}1,170 \\
21.1\end{array}$ & $\begin{array}{l}617 \\
12.1\end{array}$ & $\begin{array}{l}587 \\
10.2\end{array}$ & $\begin{array}{l}53 \\
10.9\end{array}$ \\
\hline
\end{tabular}


usually results in a high longitudinal Young's modulus (Bergander and Salmén 2000).

- Unlike spruce, heartwood of yew contains large amounts of extractives (Table 3), which, however, vary depending on provenance, variety, habitat, age and position within the stem. Being integrated in the tracheid cell wall, it is conceivable that extractives not only improve the natural durability but also function as "flexibilizer" and influence the tendency of cell wall layers to slide. This means that extractives might influence the elasticity on the cellular level.

A comparison between our dynamic Young's moduli for spruce and statically determined values given in literature reveals a higher relative increase for $E_{\mathrm{R}}$ and $E_{\mathrm{T}}$ than for $E_{\mathrm{L}}$, which confirms our theoretical assumption mentioned above in the section "Calculation of Young's and shear moduli". It is difficult to derive the corresponding static Young's moduli from this non-uniform tendency. Nevertheless, a comparison between both species is possible by building quotients of the determined Young's moduli (Table 4). The reference values in Table 4 are based on statically determined data published for softwoods by Halász and Scheer (1986). Since the relative increase of our dynamically determined values is higher for $E_{\mathrm{R}}$ and $E_{\mathrm{T}}$ than for $E_{\mathrm{L}}$, our quotients $E_{\mathrm{L}} / E_{\mathrm{T}}$ and $E_{\mathrm{L}} / E_{\mathrm{R}}$ for yew and spruce are small compared to the values of Halász and Scheer (1986). When compared to each other, $E_{\mathrm{L}} / E_{\mathrm{T}}$ and $E_{\mathrm{L}} / E_{\mathrm{R}}$ are smaller for yew than for spruce, which indicates yew to be 1.5-2 times stiffer than spruce in the transverse direction.

$E_{\mathrm{R}} / E_{\mathrm{T}}$ is 1.8 for yew and 1.5 for spruce. The relatively higher radial Young's modulus for yew can be explained with the high ray percentage. The reinforcing effect of rays results in a higher radial stiffness (Burgert 2000).

Wood shows a fibrous characteristic in the longitudinal direction. The longitudinal Young's modulus predominantly depends on the MFA of the $S_{2}$. When loaded in the transverse direction, however, wood has to be considered as a cellular material. As a result, the radial and tangential stiffness primarily depend on density. The higher the density, the higher the radial and tangential Young's modulus (e.g. Burgert et al. 2001). On the microscopic level, density depends on the cell wall/lumen aspect ratio; on the macroscopic level, it also depends on the width of tree rings. The narrower the tree rings of gymnosperms, the higher the density. The relatively thick cell walls and small lumens of yew tracheids (Table 5; Wagenführ 2000), together with tree rings some of which are extremely narrow, cause the high transverse stiffness. While tangential stiffness seems to depend exclusively on density, radial stiffness is additionally influenced by the volume fraction of rays (Burgert et al. 2001).

Possibly the large amount of extractives (Table 3 ) influences the transverse stiffness of yew as well. For larch wood, Grabner et al. (2005) found increasing extractives content to go hand-in-hand with better mechanical properties (such as a higher Young's modulus) in the transverse direction. 
Table 3 Extractives content of yew and spruce wood

Table 4 Quotients of Young's moduli: comparison of our results and reference values

\begin{tabular}{lll}
\hline & $\begin{array}{l}\text { Ethanol benzene } \\
\text { solubility (\%) }\end{array}$ & $\begin{array}{l}\text { Hot water } \\
\text { solubility (\%) }\end{array}$ \\
\hline $\begin{array}{l}\text { Taxus baccata } \text { L. } \\
\text { (Mertoglu-Elmas 2003) }\end{array}$ & $10.2-20.6$ & $6.4-16.2$ \\
$\begin{array}{l}\text { Taxus brevifolia, T. cuspidata } \\
\text { (Wagenführ 2000) }\end{array}$ & $7.4-14.3$ & $0.3-14.2$ \\
$\begin{array}{l}\text { Picea abies } \\
\text { (Wagenführ 2000) }\end{array}$ & $0.6-2.3$ & 2.0 \\
\hline
\end{tabular}

\begin{tabular}{llll}
\hline & $E_{\mathrm{L}} / E_{\mathrm{T}}$ & $E_{\mathrm{L}} / E_{\mathrm{R}}$ & $E_{\mathrm{R}} / E_{\mathrm{T}}$ \\
\hline Yew & 7.3 & 4.0 & 1.8 \\
Spruce & 11.7 & 7.6 & 1.5 \\
Gymnosperms (Halász & 20 & 11.8 & 1.7 \\
$\quad$ and Scheer 1986) & & & \\
\hline
\end{tabular}

Table 5 Cellular dimensions of yew and spruce tracheids

\begin{tabular}{lll}
\hline & Yew & Spruce \\
\hline Length $(\mu \mathrm{m})$ & $1,550 \ldots 1,950 \ldots 2,250$ & $1,300 \ldots 2,800 \ldots 4,300$ \\
Lumen $(\mu \mathrm{m})$ & $5 \ldots 9 \ldots 14$ & $3 \ldots 17 \ldots 22$ \\
Wall thickness $(\mu \mathrm{m})$ & $\mathrm{EW}^{\mathrm{a}} 4.2$ & 3.5 \\
& $\mathrm{LW}^{\mathrm{b}} 7.7$ & 10.7 \\
\hline
\end{tabular}

\footnotetext{
a Earlywood
}

b Latewood

\section{Shear moduli}

The dynamic shear moduli of spruce (Table 2) determined in this study are roughly in the same range as the statically determined values of DIN 68364 (1979). This means that only our dynamic Young's moduli, not the shear moduli, are significantly larger than static reference values.

As expected, the shear moduli of yew are extremely high (1,600-1,700 MPa for $G_{\mathrm{LR}}$ and $G_{\mathrm{LT}}$ and $>300 \mathrm{MPa}$ for $G_{\mathrm{RT}}$ ). Compared to spruce, $G_{\mathrm{LR}}$ and $G_{\mathrm{LT}}$ are about three times as high, $G_{\mathrm{RT}}$ even six times. Consequently, the shear moduli of yew clearly exceed those of other softwoods and even those of most European deciduous wood species such as maple, birch, oak and ash; beech perhaps matches most closely.

The high shear modulus of yew must result from the cellular structure of its tracheids. A shear strain causes bending strains in the tracheid cell walls, i.e. besides the ray percentage and the connection of cells by means of the middle lamella, the shear modulus primarily depends on the bending stiffness of cell walls. Particularly the thickness of a cell wall influences its bending stiffness, but also the MFA of the $S_{2}$. When modelling the elastic properties of softwood, Astley et al. (1998) found out that $G_{\mathrm{LR}}$ and $G_{\mathrm{LT}}$ can double or even 
Table 6 Quotients of shear moduli: comparison of our results and reference values

\begin{tabular}{llcc}
\hline & $\mathrm{G}_{\mathrm{LR}} / \mathrm{G}_{\mathrm{LT}}$ & $\mathrm{G}_{\mathrm{LR}} / \mathrm{G}_{\mathrm{RT}}$ & $\mathrm{G}_{\mathrm{LT}} / \mathrm{G}_{\mathrm{RT}}$ \\
\hline Yew & 1.1 & 4.7 & 4.5 \\
Spruce & 1.1 & 11.6 & 11.1 \\
Spruce (Bucur and Archer 1984) & 1.1 & 11.5 & 10.5 \\
\hline
\end{tabular}

triple with an increasing MFA. This could probably be ascribed to a transverse stiffening effect. A large MFA as a possible explanation for the relatively small Young's modulus of yew in longitudinal direction has already been discussed (see Material). Since, with respect to the lumen, the tracheid walls of yew are clearly thicker, as well, than those of spruce (Table 5), the high stiffness of yew tracheids is not surprising. A further stiffening effect is generated by the high ray percentage of yew wood (Burgert 2000).

Due to their thin cell walls, earlywood tracheids are weak points in the softwood tissue. As a consequence, predominantly earlywood tracheids are deformed by shear strains within the elastic range. The density gradient between earlywood and latewood tracheids is considerably smaller for yew than for spruce (Table 5); thus, the dimensions of yew tracheids are more homogeneous in the radial direction. Therefore, earlywood zones of yew do not represent such pronounced weak points as those of spruce.

In Table 6, the proportions of the determined shear moduli are compared among each other and with values from Bucur and Archer (1984) who worked with transverse waves of $1 \mathrm{MHz}$ frequency as well. The quotients determined for spruce highly agree with those of Bucur and Archer (1984). Within both species, $G_{\mathrm{LR}}$ and $G_{\mathrm{LT}}$ were in the same range (with $G_{\mathrm{LR}}$ being slightly higher than $G_{\mathrm{LT}}$ ). It turned out that the bending stiffness of yew tracheids has a strong effect on the shear modulus particularly in the RT plane.

Influence of wood moisture content

\section{Sorption isotherms}

Mainly due to its large amount of extractives, the influence of moisture content on the elastic constants is relevant for yew wood. Both wood species being exposed to the same variations of relative humidity, the measured sorption isotherms reveal lower moisture content for yew compared to spruce (Fig. 2). Nzokou and Kamdem (2004) found out that extractives lower the equilibrium moisture content, particularly at higher relative humidities. Our results confirm these findings.

According to Siau (1984), the fibre saturation point (FSP) corresponds to the moisture content of a wood specimen placed in a relative humidity of $98 \%$. The sorption isotherms, extrapolated up to this relative humidity, indicate an FSP of $24 \%$ for yew and $30-31 \%$ for spruce (Fig. 2). Since a further increase 
in wood moisture content has no influence on the mechanical properties of wood, we have only tested below the FSP.

\section{Influence of moisture content on sound velocities}

Sound velocity decreases dramatically with moisture content up to the FSP (Sakai et al. 1990), which could be confirmed by our investigations (Table 7). Sakai et al. (1990) found the decrease to run linearly up to the FSP. This results from the fact that sound velocity is directly related to the presence of bound water (Bucur 1995). We obtained this tendency as well (Fig. 3), only $c_{\mathrm{LL}}$ deviates from this linear trend.

A comparison of group 1 (honey) and group 2 (carbon; at $20^{\circ} \mathrm{C}$ and $65 \%$ RH) shows that both groups do not significantly differ in their ultrasound velocities. Thus, both groups are comparable; a strong influence of the coupling medium was not noticeable. In terms of $c_{\mathrm{TT}}$ of spruce, however, group 1 (honey) clearly deviates from group 2 (carbon). It is conceivable that we did not detect the identical wave peak in both groups due to higher attenuation by the carbon disks and worse coupling, respectively.

\section{Influence of moisture content on elastic constants}

For the purpose of comparison between the elastic constants determined in this study and reference values from literature, correction factors should be considered. For the evaluation of the moisture influence, however, it is not required since it is sufficient to examine the relative increase or decrease of elastic constants.

As found for the sound velocities, the elastic constants of groups 1 (honey) and 2 [carbon; at $20^{\circ} \mathrm{C}$ and $65 \% \mathrm{RH}$ (Table 8)] are also more or less in the

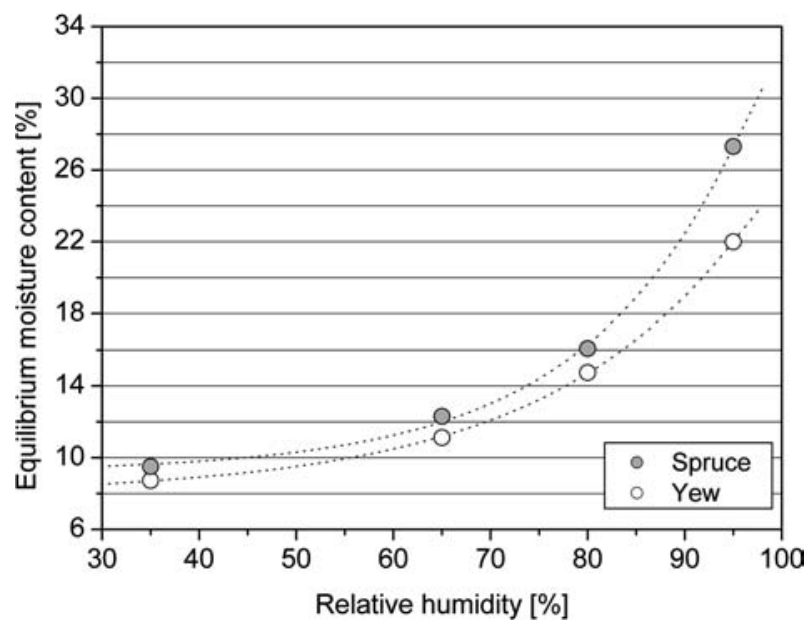

Fig. 2 Sorption isotherms for yew and spruce specimens 


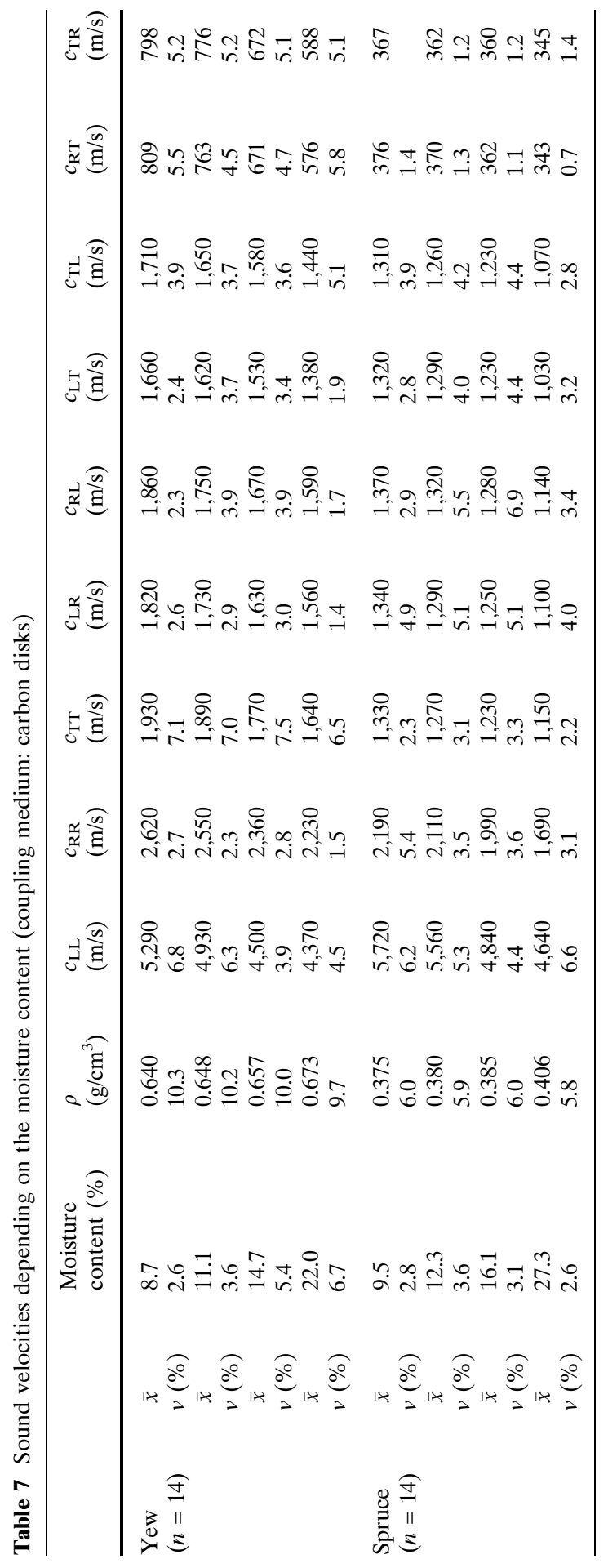




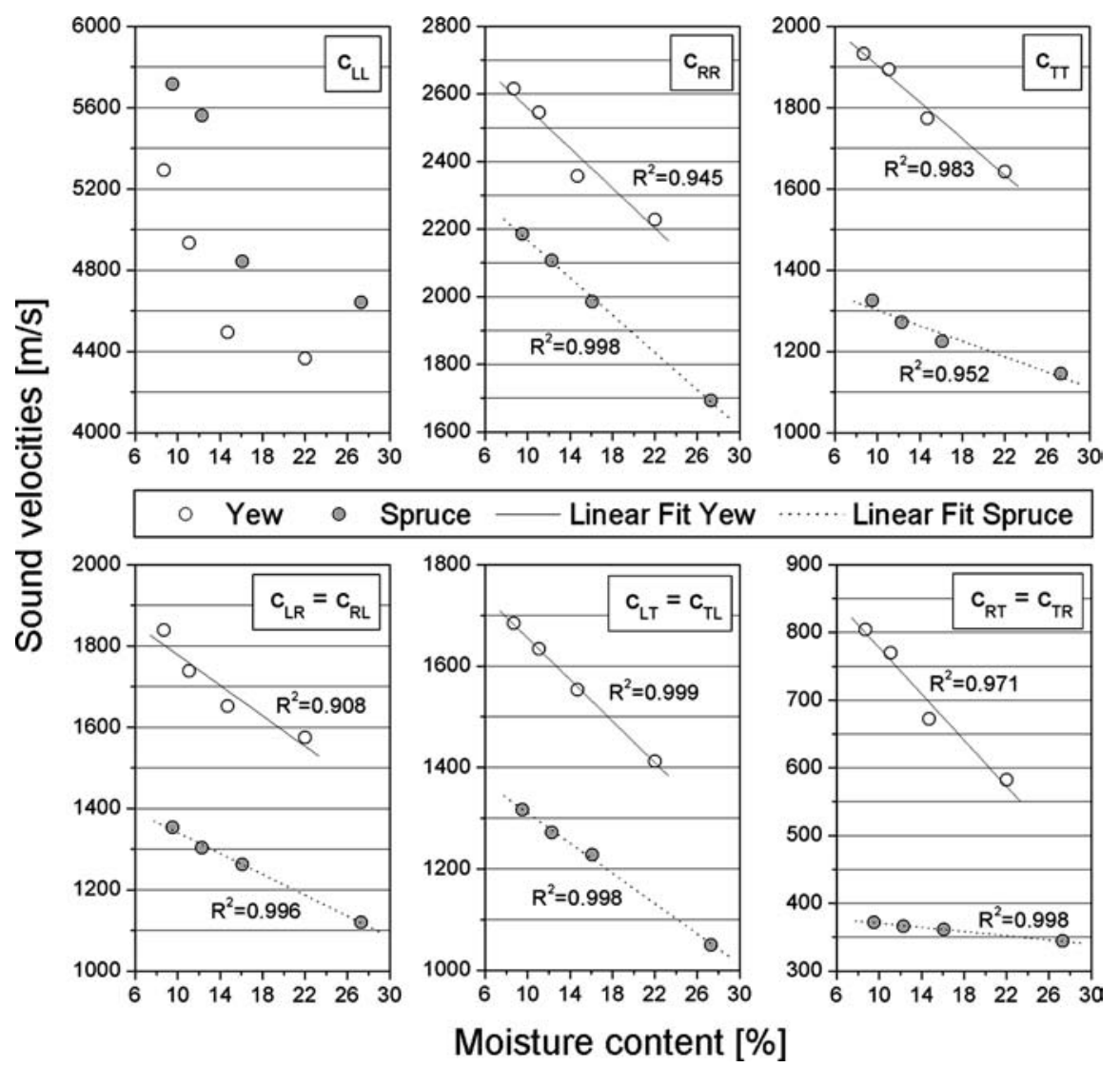

Fig. 3 Influence of moisture content on the sound velocities

same order of magnitude. While the slightly lower values $E_{\mathrm{L}}$ and $E_{\mathrm{R}}$ for spruce in group 2 (carbon) are caused by the lower density of the specimens, the reason for the clearly lower $E_{\mathrm{T}}$ in the same group remains unclear. The $E_{\mathrm{T}}$ values of group 1 (honey) seem more plausible since $E_{\mathrm{T}} / E_{\mathrm{R}}$ is about 1.5 in this group.

Figure 4 shows the percentage decrease of elastic constants with moisture content. The decrease is based on the initial value at $35 \% \mathrm{RH}$. For the range of moisture content investigated in this study (between 8.7 and $22.0 \%$ for yew and between 9.5 and $27.3 \%$ for spruce), the decrease of Young's and shear moduli is described as approximately linear in literature (Kollmann 1951; Kufner 1978; Bodig and Jayne 1982; Booker et al. 1996). As found for $c_{\mathrm{LL}}, E_{\mathrm{L}}$ deviates from this linear correlation as well, the decrease running exponentially with a decrease pattern being quite similar for both species. In contrast, the remaining five elastic constants decrease linearly with moisture content (Fig. 4).

We observed the most conspicuous difference between both wood species for $G_{\mathrm{RT}}$. Up to $95 \% \mathrm{RH}, G_{\mathrm{RT}}$ drastically decreased for yew (45\% based on 


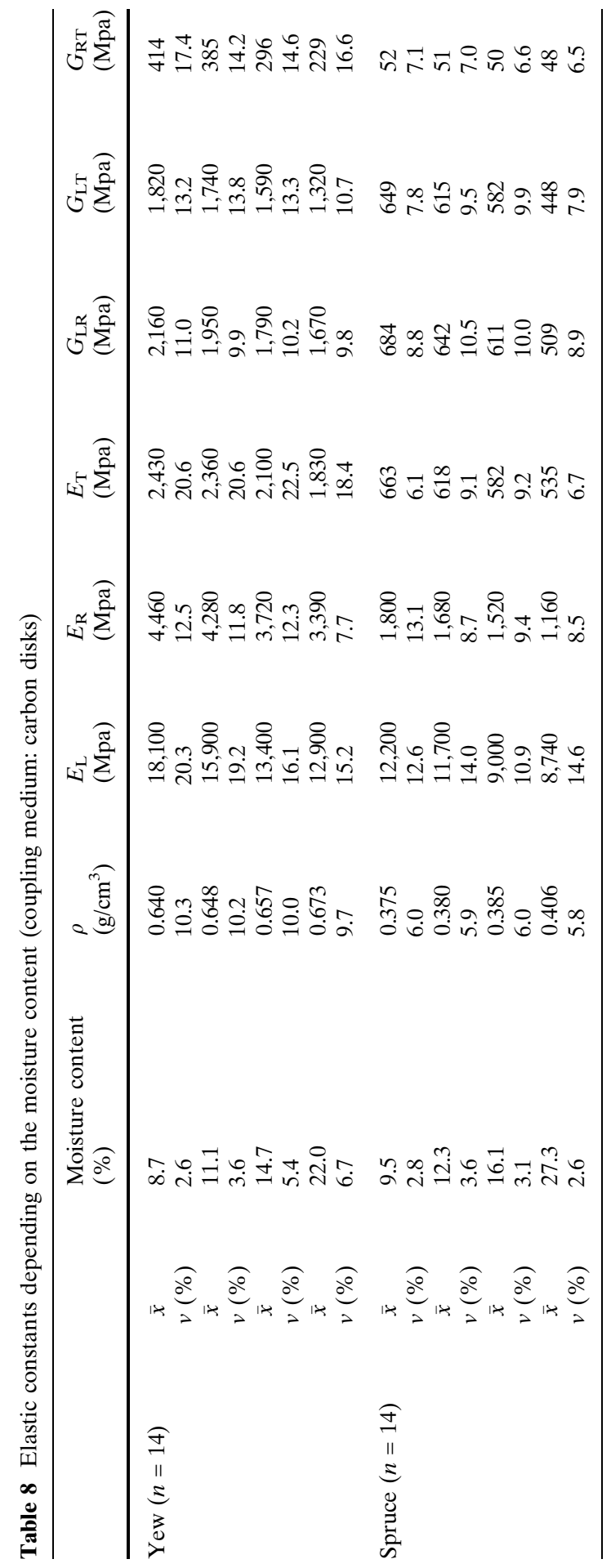


the initial value) but only slightly for spruce ( $8 \%)$. What exactly causes these large differences is difficult to interpret. Since $E_{\mathrm{R}}$ decreased equally for both species while a clearly stronger decrease of $E_{\mathrm{T}}$ was found for yew, the assumption is that the large differences in $G_{\mathrm{RT}}$ are primarily influenced by different decreases of stiffness in the tangential direction. The Young's moduli $E_{\mathrm{L}}, E_{\mathrm{R}}$ and $E_{\mathrm{T}}$ decreased between 24 and $29 \%$ for yew and, less homogeneously, between 19 and $35 \%$ for spruce. For the latter, the decrease is slightest in the tangential and strongest in the radial direction. The decrease in shear moduli $G_{\mathrm{LR}}$ and $G_{\mathrm{LT}}$ is between 23 and $31 \%$ for both species.

Further factors influencing the elastic behaviour

We speculated about a large MFA being the reason for the comparably low longitudinal Young's modulus of yew. The high transverse stiffness was explained with well-known properties such as high density, high ray percentage and the large amount of extractives. There are further factors, which influence
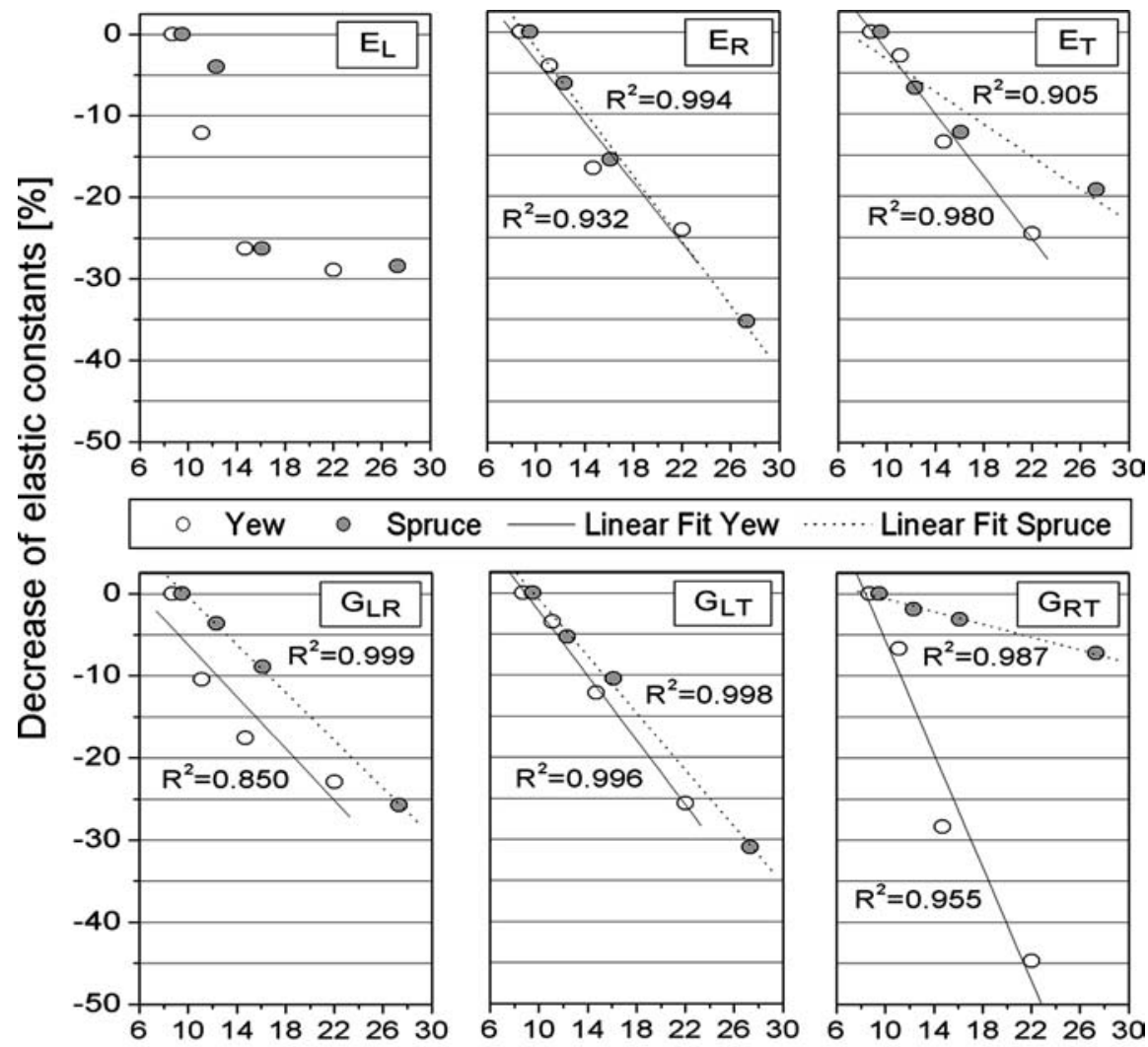

Moisture content [\%]

Fig. 4 Percentage decrease of elastic constants with moisture content 
elasticity, but they have not been evaluated for yew wood so far and are not considered in this study. For example, Bergander and Salmén (2000) point out the importance of the thickness and the MFA of the S1 and S3 layers for radial and tangential stiffness. The percentage of the three main wood polymers influences stiffness as well. Longitudinal elasticity is primarily affected by cellulose, whereas the properties of hemicelluloses define transverse elasticity (Bergander and Salmén 2002).

\section{Conclusions}

The results conformed to our expectations: The longitudinal ultrasound velocity is lower for yew than for spruce, presumably due to the short tracheids and the irregular grain of yew wood. The transverse Young's moduli are 1.5-2 times, the shear moduli even 3-6 times higher for yew compared to spruce. The reason for the large differences between both species in the moisture-induced decrease of $G_{\mathrm{RT}}$, however, remains unclear.

Our study confirms the exceptional mechanical characteristics of yew wood and shows that high-density wood species need not inevitably have a high longitudinal Young's modulus. The correlation between density and Young's modulus is valid within a wood species, but only in a limited way for speciesspanning comparisons. When compared to other gymnosperms, the stiffness of yew wood seems to be an outlier in both the longitudinal (low values) and transverse (high values) direction.

From our results we conclude that anatomical features such as the high ray percentage, the MFA and presumably the large amount of extractives must fulfil important functions for the elastomechanical behaviour of yew wood, since those are obviously the properties in which yew and spruce mainly differ.

Therefore, the following questions have to be answered by subsequent studies:

- Is the MFA of yew wood generally larger than that of other gymnosperms?

- How do yew rays influence wood stiffness?

- With respect to their elastomechanical properties, what are the differences between normal and extracted yew wood?

Acknowledgment This work was supported by the European Cooperation in the field of scientific and technical research (COST, Action E35).

\section{References}

Albers K (1970) Querdehnungs- und Gleitzahlen sowie Schub- und Scherfestigkeiten von Holzwerkstoffen, Dissertation, Hamburg, p 117

Astley RJ, Stol KA, Harrington JJ (1998) Modelling the elastic properties of softwood - Part II: the cellular microstructure. Holz Roh- Werkst 56:43-50

Bariska M (1998) Verwendung des Eibenholzes gestern und heute. Schweiz Z Forstwes 149:340348 
Becker H (1967) Possibilities of using ultrasonic waves in testing wood and particle board. Holzforschung 21:135-145

Bergander A, Salmén L (2000) Variations in transverse fibre wall properties: relations between elastic properties and structure. Holzforschung 54:654-660

Bergander A, Salmén L (2002) Cell wall properties and their effects on the mechanical properties of fibers. J Mater Sci 37:151-156

Bodig J, Jayne BA (1982) Mechanics of wood and wood composites. Van Nostrand Reinhold, New York, p 712

Booker RE, Froneberg J, Collins F (1996) Variation of sound velocity and dynamic Young's modulus with moisture content in the three principal directions. In: Proceedings of 10th international symposium on non-destructive testing of wood, Lausanne, Switzerland

Bucur V (1995) Acoustics of wood. CRC Press, Boca Raton, p 284

Bucur V (1996) Acoustics of wood. Mater Sci Forum Vol 210-213:101-108

Bucur V, Archer RR (1984) Elastic constants for wood by an ultrasonic method. Wood Sci Technol 18:255-265

Burgert I (2000) Die mechanische Bedeutung der Holzstrahlen im lebenden Baum, Dissertation, Hamburg, p 173

Burgert I, Bernasconi A, Niklas KJ, Eckstein D (2001) The influence of rays on the transverse elastic anisotropy in green wood of deciduous trees. Holzforschung 55:449-454

Burmester A (1965) Relationship between sound velocity and the morphological, physical and mechanical properties of wood. Holz Roh- Werkst 23:227-236

DIN 68364 (1979) Kennwerte von Holzarten - Festigkeit, Elastizität, Resistenz

Ehlbeck J (1967) Durchbiegungen und Spannungen von Biegeträgern aus Holz unter Berücksichtigung der Schubverformung, Dissertation, Karlsruhe, p 136

Görlacher R (1990) Klassifizierung von Brettschichtholzlamellen durch Messung von Longitudinalschwingungen, Dissertation, Karlsruhe, p 160

Grabner M, Müller U, Gierlinger N, Wimmer R (2005) Effects of heartwood extractives on mechanical porperties of larch. IAWA J 26:211-220

Halász R, Scheer C (1986) Holzbau-Taschenbuch, Ernst Verlag für Architektur und technische Wissenschaften, Berlin

Jakubczyk B (1966) Technical properties of the yew wood from the preserve Wierzchlas. Sylwan 10:79-86

Kollmann F (1951) Technologie des Holzes und der Holzwerkstoffe. Springer, Berlin Heidelberg New York, p 1050

Kollmann F, Krech H (1960) Dynamic measurement of damping elasticity and elastic properties of wood. Holz Roh- Werkst 18:41-54

Kucera L (1998) Das Holz der Eibe. Schweiz Z Forstwes 149:328-339

Kufner M (1978) Modulus of elasticity and tensile strength of wood species with different density and their dependence on moisture content. Holz Roh Werkst 36:435-439

Lee IDG (1958) A non-destructive method for measuring the elastic anisotropy of wood using an ultrasonic pulse technique. J Inst Wood Sci 1:43-57

Märki C, Niemz P, Mannes D (2005) Comparative studies on selected mechanical properties of yew and spruce. Schweiz Z Forstwes 156:85-91

Markwardt LJ, Wilson TRC (1935) Strength and related properties of woods grown in the United States, US Department of Agriculture, Forest Service, Tech Bull, Washington

Mertoglu-Elmas G (2003) Chemical components of heartwood and sapwood of common yew (Taxus baccata L.). J Environ Biol 24:489-492

Neuhaus FH (1981) Elastizitätszahlen von Fichtenholz in Abhängigkeit von der Holzfeuchtigkeit, Dissertation, Bochum, p 162

Niemz P, Kucera L, Bernatowicz G (1999) Studies on the effect of grain angle on the propagation velocity of soundwaves in wood. Holz Roh- Werkst 57:225-225

Nzokou P, Kamdem DP (2004) Influence of wood extractives on moisture sorption and wettability of red oak (Quercus rubra), black cherry (Prunus serotina), and red pine (Pinus resinosa). Wood Fiber Sci 36:483-492 
Sakai H, Minamisawa A, Takagi K (1990) Effect of moisture content on ultrasonic velocity and attenuation on woods. Ultrasonics 28:382-385

Schwab E, Polaczek P (1977) Determination of moduli of rigidity of wood by static torsional tests - contribution to revision of DIN 52190. Holz Roh- Werkst 35:23-27

Sekhar AC, Sharma RS (1959) A note on mechanical properties of Taxus baccata. Indian Forester 85:324-326

Sell J (1997) Eigenschaften und Kenngrössen von Holzarten. Baufachverlag, Dietikon, p 87

Siau JF (1984) Transport processes in wood. Springer, Berlin Heidelberg New York, p 245

Wagenführ R (2000) Holzatlas, Fachbuchverlag Leipzig, München, p 707 